\title{
LA CUESTIÓN TERRITORIAL EN EL PSOE DURANTE LA II REPÚBLICA
}

\author{
Daniel MOLINA JIMÉNEZ \\ Universidad Nacional de Educación a Distancia (UNED)
}

Recibido: $28 / 04 / 2013$

Aceptado: 04/11/2013

RESUMEN: El debate sobre la cuestión regional en el PSOE durante la II República española fue muy amplio. Existe una lucha entre una concepción centralista y otra federal, en cualquier caso, ambas van a estar vinculadas en el discurso de los socialistas a los intereses de la clase obrera.

PALABRAS CLAVE: Federalismo, centralismo, Estado, nacionalismo, trabajadores.

ABSTRACT: The debate on the issue in the PSOE regional during the Second Spanish Republic was very wide. There is a fight between a centralized approach and other federal, in any case, both are going to be linked in the speech of the socialists to the interests of the working class.

KEYWORDS: Federalism and centralist State, nationalism, workers.

\section{INTRODUCCIÓN}

El papel jugado por los socialistas durante la II República fue importante. Especialmente durante el primer bienio (1931-1933), periodo en el que los el PSOE entra en el gobierno junto con los republicanos y realiza una serie de reformas sociales. La arquitectura institucional también ocupa un lugar relevante. Los socialistas van a defender a lo largo del periodo distintas soluciones políticas para la articulación del Estado español que se integrará dentro de las expectativas de transformación del régimen republicano.

Antes de entrar en materia, basta hacer una revisión de la bibliografía para darse cuenta que el objeto de estudio que presentamos es una novedad dentro de la historiografía española. Hasta hace 30 años, la bibliografía sobre el PSOE (trayectoria histórica, relaciones políticas, ideología, programa, líderes, etc), era bastante precaria. Junto a algunos estudios individuales de historiadores, encontrábamos numerosas hagiografías de antiguos militantes, lo que mostraba trabajos de interés pero en general, poco rigurosos al carecer de un estudio 
sistemático de la bibliografía sobre la materia $\mathrm{y}$, especialmente de fuentes primarias. No obstante, durante ese tiempo, entre los aspectos mejor estudiados hay que destacar las aproximaciones a algunas de las figuras más relevantes del socialismo español -por ejemplo los trabajos de Emilio Lamo de Espinosa sobre Julián Besteiro ${ }^{1}$ o de Virgilio Zapatero sobre Fernando de $\operatorname{los}_{\text {Ríos }}^{2}$ o de Indalecio Prieto, de Alfonso Saiz Valdivieso ${ }^{3}$-. De igual modo, hay que señalar algunos trabajos hechos por historiadores. A este respecto son varios los acercamientos a la radicalización de la izquierda socialista tras 1933 - destacan los libros de Marta Bizcarrondo ${ }^{4}$, Andrés de Blas ${ }^{5}$, Manuel Contreras ${ }^{6}$ y Santos Juliá 7 , entre otros-. Sin embargo, estas aproximaciones eran contingentes y circunscritas a momentos determinados de la historia del socialismo. No existía, en ese momento, ninguna aproximación a otras épocas como la Guerra Civil o la dictadura de Franco. Tras la instauración de la democracia, han aparecido algunos trabajos, casi hagiográficos, realizados por veteranos militantes socialistas que han tratado de dejar constancia de su experiencia vital.

En la última década del siglo pasado, el panorama varió de forma significativa. A lo largo de los últimos años, han visto la luz varias obras que analizan la trayectoria del socialismo español, de forma parcial o en su conjunto, durante la Guerra Civil y el exilio y la Transición, así como numerosas tesis doctorales sobre el PSOE y el socialismo español. Entre estas obras, de interés muy diferente, hay que destacar los trabajos de Santos Juliá, bien dentro de los Anales del Socialismo, resultado último de las Jornadas organizadas por la Fundación Pablo Iglesias en

\footnotetext{
${ }^{1}$ Lamo De Espinosa, E. Política y filosofia en Julián Besteiro. Madrid: Editorial Cuadernos para el Dialogo, 1973.

${ }^{2}$ ZAPATERO, V. Fernando de los Ríos: biografía intelectual. Valencia: Diputación de Granada, D. L. 1999. También: Fernando de los Ríos, intelectual y político. Granada: Diputación de Granada: Universidad de Granada, D.L. 1997.

${ }^{3}$ Saiz Valdivieso, A. Indalecio Prieto. Crónica de un corazón. Barcelona: Planeta, 1984.

${ }^{4}$ Bizcarrondo, M. Octubre de 1934: Reflexiones de una revolución. Madrid: Ayuso, D.L. 1977. También: Araquistain y la crisis socialista en la II República: Leviatán (1934-1936). Madrid: Siglo XXI, 1975.

5 DE BLAS, A. El socialismo radical en la Segunda República. Madrid: Tucar, 1978.

${ }^{6}$ CONTRERAS, M. El PSOE en la II República: organización e ideología. Madrid: Centro de Investigaciones Sociológicas, 1981.

${ }^{7}$ JuLiá, S. La izquierda del PSOE (1935-1936). Madrid: Siglo XXI, 1977.

${ }^{8}$ CAStillo, S. [et al.] El socialismo en España: desde la fundación del PSOE hasta 1975. Madrid: Pablo Iglesias, 1986.
} 
1985 y 1986, bien dentro de su contribución a la historia del socialismo español ${ }^{9}$. También es preciso citar el trabajo de Abdón Mateos ${ }^{10}$ relativo a la acción del PSOE durante la dictadura de Franco. Finalmente, hay que mencionar la aparición de una buena obra de conjunto, The Spanish Socialist Party. A history of factionalism, debida al británico Richard Gillespie ${ }^{11}$ y cuya versión castellana ha sido publicada con una amplia difusión, y una excelente monografía sobre el período de la Guerra Civil de Helen Graham, Socialism and War. The Spanish Socialist Party in power and crisis, 1936-1939 ${ }^{12}$, que constituye la más reciente aportación al tema.

Sin embargo, en todo ese rastreo bibliográfico, observamos una carencia importante: No existe un estudio que analice la evolución de la idea de patria en el PSOE. Tan solo encontramos un capítulo de Carlos Forcadell en un estudio sobre el discurso nacional ${ }^{13}$, en donde se realiza una breve, pero sumamente interesante, interpretación de la evolución nacional; un libro colectivo de reciente publicación, Izquierdas y nacionalismos, coordinado por Javier Moreno Luzón, en donde se muestran algunas referencias específicas sobre el patriotismo socialista o la relación entre el PSOE y los partidos nacionalistas ${ }^{14}$, así como varios estudios referidos a la evolución de la idea de España en la izquierda, realizados por Alejandro Quiroga, Sebastian Balfour ${ }^{15}$ y Núñez Seixas ${ }^{16}$. De manera que no encontramos en la historiografía un estudio general sobre la evolución de la cultura política nacional del PSOE.

9 JuLIÁ, S. Los socialistas en la política española: (1879-1982). Madrid: Taurus, 1997. Este trabajo de Juliá tiene interés en la medida en que se centra en la trayectoria política del socialismo, es decir, se trata de una obra de historia política no un análisis ideológico del partido.

${ }^{10}$ MATEOS, A. El PSOE contra Franco: continuidad y renovación del socialismo español: 19531974. Madrid: Pablo Iglesias, 1993. También: Las izquierdas españolas desde la Guerra Civil hasta 1982: organizaciones socialistas, culturas políticas y movimientos sociales. Madrid: Universidad Nacional de Educación a Distancia, 1997.

${ }^{11}$ GillesPIE, R. Historia del Partido Socialista Obrero español. Madrid: Alianza, D.L. 1988.

12 Graham, H. El PSOE en la guerra civil. Poder, crisis y derrota (1936-1939). Barcelona: Debate. 2005.

${ }^{13}$ Forcadell, C, SAlomón, P, SAz, I. (eds.). Discursos de España en el siglo XX. Valencia: Universitat de València, D.L. 2009.

14 Moreno Luzón, J. Izquierdas y nacionalismos en la España contemporánea. Madrid: Fundación Pablo Iglesias, 2011.

${ }^{15}$ BALFOUR, S. España reinventada: nación e identidad desde la transición. Barcelona: Ediciones Península, 2007.

${ }^{16}$ NúÑ̃z SEIXAS, X.M.. Patriotas y demócratas. El discurso nacionalista español después de Franco. Madrid: Catarata, 2010. 


\section{RETÓRICA ANTINACIONALISTA E INTERNACIONALISTA}

La situación de partida, es decir, la ausencia de una monografía sobre el tema en cuestión, tal vez obedezca a la costumbre un tanto inexplicable de la historiografía de distinguir las corrientes de pensamiento a partir de quienes se identificaban directamente con ellas: así, sucede por el ejemplo, con el republicanismo o con el progresismo, que se estudia analizando a aquellos autores, líderes o partidos que dicen ser republicanos o progresistas. Sin embargo, el republicanismo o el progresismo clásico no es una corriente doctrinal de pensamiento, sino un conjunto de referentes y significaciones sociales que pueden ser ulteriormente adoptados y adaptados por muy distintos autores y organizaciones. Sucede lo mismo con los estudios del nacionalismo: solo se ha estudiado la idea de nación de una manera abstracta o genérica a través de todos aquellos elementos intervinientes en las teorías normativas de la nación olvidando que la idea de patria puede contener elementos diferenciadores y específicos en grupos y movimientos que, en principio, no definen su ideología en torno al hecho nacional como programa y acción política. Como ha explicitado Hobsbawm, el nacionalismo no se identificaba necesariamente con ninguna formación del espectro político. Entre los movimientos nacionales que no tenían todavía su propio Estado había unos que se identificaban con la derecha o con la izquierda, mientras que otros eran indiferentes a ambas. Por otra parte, había movimientos, y no eran los menos importantes, que movilizaban a hombres y mujeres sobre una base nacional, pero, de forma accidental porque su primera preocupación era la liberación social. Si es cierto que la identificación nacional era, o llegó a ser, un factor importante en la política de los Estados, pero es totalmente erróneo considerar que la causa nacional era incompatible con cualquier otra ${ }^{17}$.

Los socialistas mantienen un discurso de rechazo a los principios del nacionalismo que será una de las tensiones que tendrá el régimen republicano. Ese rechazo incluye tanto a los nacionalismos burgueses de la derecha como a los partidos de las clases altas de la periferia. Lo que encarna la convivencia y la solidaridad entre los pueblos para el PSOE es el internacionalismo. El nacionalismo es rechazado por artificioso y por no representar realmente la voluntad de los intereses verdaderos del pueblo. Así lo pone de manifiesto el editorial de La Aurora Social. «Los nacionalismos de los pueblos, aun de aquellos que figuran con caracteres y rasgos más acusados y diferenciales, no siempre expresan una voluntad unánime profundamente sentida por todos los habitantes que integran una entidad geográfica, sino que ellos señalan un deseo fuerte,

${ }^{17}$ Hobsbawm, E. La era del imperio, 1875-1914. Barcelona: Crítica, 2009, pág. 153. 
perfectamente delineado, de crear esa voluntad nacional, aislada, separada, de otras más amplias y comunes ${ }^{18}$ ». De este modo «el socialismo traza una órbita más amplia y generosa sobre estos problemas nacionalistas, extiende su visión humana por encima de lo que son, a veces residuos o reminiscencias políticas y sociales pretéritas ${ }^{19} \gg$. Los socialistas no pretenden borrar los rasgos y características de un pueblo y menos prescindir de lo que constituya el meollo espiritual formado de los habitantes de una región; "pero no pretende crear nuevas y forzadas diferencias, ni separar con barreras artificiales los límites regionales que la marcha de la sociedad va borrando más intensamente de día en día. [...] No es el Socialismo enemigo de las libertades propias de los pueblos, ni partidario de fundir con otros sus características, ni enemigo de sus costumbres. Lo que no quiere el Socialismo son artificiales creaciones de nacionalidades, ilógicas e incompresibles hoy» ${ }^{20}$.

Como ha explicado Gabriel Jackson republicanos y socialistas sabían, en las postrimerías de la Dictadura de Primo de Rivera, que la Monarquía se estaba enfrentando a una profunda crisis de legitimidad que hacía enormemente problemática su supervivencia ${ }^{21}$. También Julián Casanova ha sintetizado las causas del derrumbe de la Monarquía Alfonsina: «El suicidio de la Monarquía comenzó a fraguarse en los tres últimos años de la dictadura de Primo de Rivera, cuando la negativa de éste a devolver el poder al régimen parlamentario y la incapacidad del rey para forzarle a que así lo hiciera, consolidaron la identificación entre el monarca y el dictador y abrieron un periodo de conspiraciones y pronunciamientos para derribar la Dictadura con el recursos decimonónico al espadón ${ }^{22} \gg$. El objetivo de los Socialistas, va a consistir en tratar de ser el catalizador de todo este movimiento de rechazo y de cambio.

Tal y como explica Santos Juliá, en 1930, la extendida conciencia de que el problema de España era de índole política, más que de constitución de la sociedad, se expresó en el dilema excluyente monarquía o República. La primera

18 «Socialismo y nacionalismo». La Aurora Social, 2 de Octubre de 1931. Relatos similares los encontramos en: SÁNCHEZ RiverA, J. «El nacionalismo: he aquí el enemigo». El Socialista, 1 de enero de 1931.

${ }^{19}$ Ibídem.

${ }^{20}$ Ibidem.

21 JACKSON, G. La República española y la guerra civil. Un análisis muy detallado de la crisis final de la Monarquía de Alfonso XII, como antecedentes y raíces de la implantación de la II República lo encontramos en el capítulo I. También en: PALAFOX, J. Atraso económico y democracia. La Segunda República y la economía española, 1892-1936. Barcelona: Crítica, 1991.

22 Fontana, J y Villares, R (directores). Historia de España. República y guerra civil. Casanova, J. República y guerra civil. Barcelona: Crítica, Marcial Pons, 2007, pág. 4. 
representaba en el imaginario colectivo lo viejo y caduco, el comité de administración de unos grupos sociales que habían acampado sobre la sociedad como territorio de conquista y no la dejaban crecer, la segunda simbolizaba lo joven y nuevo, y traía prendida de sus canciones la expectativa de transformación del Estado y de la vida entera: todo el mundo, en las ciudades, durante aquel año crucial, comenzó a definirse por la República ${ }^{23}$.

El PSOE es una fuerza permanentemente activa y colaboradora en las Cortes constituyentes de 1931, y participa en la redacción de la Constitución que será aprobada el 9 de diciembre de 1931. Los socialistas aprueban la Constitución porque en palabras de Fernando de los Ríos en el Parlamento, se trata de una Constitución patriótica y que gira en torno a la concepción que tienen los socialistas de España. Para Fernando de los Ríos la Constitución debía servir para romper esa inercia dialéctica de acción reacción que tanto caracterizó la vieja España del XIX. «Es preciso, pues, para nuestra Constitución, de una parte, superar la antítesis histórica que constituye el drama histórico español, y, de otra parte, superar lo que está ya superado en la experiencia, liberalismo económico y democracia inorgánica en nuestro país» ${ }^{24}$. Fernando de los Ríos argumenta en clave nacional el éxito que para los socialistas supone la Constitución. «No es una negación no, es un sentido ecuménico de la política, a virtud del cual decimos que la patria es para el Mundo, y la insertamos en él y queremos llevar al Mundo los valores hispánicos y que se tiña la Historia del color ideal de la sangre espiritual de los valores engendrados por la conciencia española. No decimos 'el Mundo para España', con aquel sentido patriótico que envenenó la conciencia de la amada Alemania. Lo que nosotros decimos es España para el Mundo. Y este es el sentido universalista orgánico de nuestro concepto de patria» ${ }^{25}$.

El internacionalismo proletario no anulaba las naciones, sino que las transformaban, las incardinan en un mundo más conectado, pero manteniéndolas como unidades políticas del mismo. Por consiguiente, no solo perviven las variables clase y nación, a veces encontrándose y otras avanzando en líneas paralelas, sino que además operan alternativamente en las dimensiones nacional e internacional, que están permanentemente interconectadas. Todo ello se encuadra, como afirma Marta Bizcarrondo, en España, en el conjunto del movimiento socialista, «de la derecha a la izquierda, de Julián Besteiro a Francisco Largo Caballero, hay una extremada dificultad para abordar el proceso histórico desde

23 JuliÁ, S. Hoy no es ayer. Madrid, RBA, 2009, pág. 10.

${ }^{24}$ Diario de Sesiones del Congreso n 32.3 de septiembre de 1931.

${ }^{25}$ Ibidem. 
una óptica de clase. "Cierto que se dan ensayos individuales, pero, son excepcionales» ${ }^{26}$. De ahí que la nación obrera sirviera para hacer apelaciones más globales. También Gillespie explica que la inmensa mayoría de los socialistas celebró en 1931 la perspectiva de un progreso gradual mediante reformas sociales y económicas ${ }^{27}$.

El internacionalismo burgués, por capitalista, es económico y competitivo, basado en intereses particulares. El internacionalismo obrero es, por lo contrario, solidario y fraternal, pues apela a los intereses generales. A nivel nacional, el internacionalismo capitalista se traduce en Estados inicialmente liberales que evolucionan hacia meras estructuras legales y políticas justificativas de la acción económica de una burguesía que satisface sus intereses particulares por encima de los de la población. Evolucionan, pues, para los socialistas, hacia Estados oligárquicos y reaccionarios. Sin embargo, las clases obreras respectivas deberían conseguir el poder político para volver a liberalizar sus naciones, democratizarlas realmente socializando los medios de producción.

Por ello los socialistas no pueden anular la realidad nacional, precisamente deben asumirla para encuadrar su actuación en el contexto correcto. Sin embargo, aun siendo nacionales, no admiten ser nacionalistas, pues consideran falsa e insolidaria la superioridad que denota el nacionalismo siendo la excusa de la burguesía para mantener su poder en el Estado y seguir internacionalizando su actividad económica. El nacionalismo es la perversión del legítimo sentimiento nacional. Esta será, en los primeros decenios, la tesis dominante en el PSOE frente al patriotismo de la burguesía española y frente a los nacionalismos periféricos.

\section{DEBATE ENTRE UNITARIOS Y FEDERALISTAS}

Tal y como ha recordado Justo Beramendi, es bien sabido que, dentro de la secuencia de los sistemas políticos de la España contemporánea, la II República trajo consigo, descontado el fallido ensayo de la República federal de 1873, varias innovaciones de gran calado que pretendían superar, en sentido modernizador, los principales factores de atraso social y político que había venido padeciendo el país desde los inicios de la revolución liberal en el primer tercio del siglo XIX: en lo político, el establecimiento de una auténtica democracia representativa, voto de la mujer incluido; en lo social, la reforma agraria y una legislación laboral acorde con

${ }^{26}$ AA.VV. El socialismo en España. Madrid: Fundación Pablo Iglesias, 1986, pág. 262.

${ }^{27}$ Gillespie, R. Historia del Partido Socialista Obrero Español. Madrid: Alianza Universidad, pág. 43. 
los tiempos; en lo religioso, la instauración de un Estado radicalmente laico; y en lo militar, la subordinación de las fuerzas armadas al poder civil. A todas estas fuentes de tensión, originadas en el siglo XIX, se había añadido en las tres décadas precedentes otra, la emergente plurinacionalidad del Estado, que se había ido ensanchando al compás del nacimiento y rápido desarrollo de los nacionalismos catalán y vasco y, en mucha menor medida, del débil nacionalismo gallego y de otros brotes de momento marginales ${ }^{28}$.

El PSOE, que en 1931 mantenía en esto una postura muy similar a la de los republicanos autonomistas, había dado más de un bandazo en este terreno. En su programa de 1918, influido por el ambiente europeo favorable al principio de las nacionalidades y por el impacto de la Revolución Rusa y la asunción bolchevique del derecho de autodeterminación, había incorporado a su programa nada menos que la «Confederación republicana de las nacionalidades ibéricas»" ${ }^{29}$. Sin embargo, a la altura de 1930-1931 esa actitud había cambiado. Si bien no manifestaba una oposición programática al federalismo, ni la cuestión nacional auguraba entre sus principales preocupaciones ni era ésa ya la vía que prefería para la articulación territorial del Estado español (como veremos más adelante). De hecho, en su congreso extraordinario de julio de 1931, atendiendo los argumentos de Fernando de los Ríos y otros, rechazó la propuesta en pro de una República federal presentada por los delegados de Valladolid con el apoyo de los de Cataluña.

El discurso Socialista va a estar condicionado por esta circunstancia. Los debates entre las posiciones federales y unitarias estarán presentes incluso antes de la instauración de la II República. Tras considerar como inverosímiles las informaciones sobre unos supuestos intentos de Prieto en agrupar las fuerzas republicanas vascas, «incluidas nacionalistas y tradicionalistas, para implantar una República vasca $»^{30}$, el PSOE cree más certera una segunda versión que indica que «se trata o se desea iniciar una acción para que surjan como fuerzas vivas las personalidades regionales con miras a un Estado federativo», condicionada a las resoluciones de los órganos de dirección del Partido. Ello se reconoce como una «propuesta acogida por la Federación Socialista Vasco-Navarra» ${ }^{31}$. En línea con el

${ }^{28}$ Un artículo de referencia para el estudio del problema regional durante la II República es: Beramendi, J. «Nacionalismos, regionalismos y autonomía en la Segunda República». En Pasado y Memoria. Revista de Historia Contemporánea, $\mathrm{n}^{\circ}$ 2, 2003.

29 Beramend, J. «Nacionalismos, regionalismos y autonomía en la Segunda República», en Pasado y Memoria. Revista de Historia Contemporánea, n², 2003. Cita tomada por BERAMENDI en: PSOE, Organización general, Madrid, s. d., págs. 3-12.

30 «Sobre alianzas con las fuerzas políticas del regionalismo». El Socialista, 25 de abril de 1930.

${ }^{31}$ Ibídem. 
discurso que mantendrá Aníbal Sánchez, Enrique de Francisco vaticina el recelo del PSOE a cualquier iniciativa republicana divisoria y unilateral por parte de los partidos catalanistas que quieren desmarcarse del movimiento republicano estatal.

En este sentido, y sin desautorizar explícitamente las gestiones de Prieto, El Socialista, publica un editorial en el que marca la pauta de prudencia ante posibles pactos con partidos republicanos locales, considerando un error pretender «iniciar la política redentora de España por pequeños movimientos de carácter regional $\gg^{32}$. Tras volver a recordar el fracaso de la República del 73 por el cantonalismo -al que considera «un peligro»-, señala: «Hay que tonificar la conciencia nacional, haciéndola concebir la esperanza de su salvación en la fusión sincera de todas las energías cívicas de las regiones en un mismo ideal: el de liberalizar y democratizar a España, para lo cual hay que destruir todas las fuerzas tradicionalistas. Las regiones alcanzarán su ideal de libertad cuando el país haya cambiado fundamentalmente sus instituciones de Gobierno. Mientras, no» ${ }^{33}$.

Los socialistas equiparan la conciencia nacional con la republicana, y señalan que la prioridad es la mejora del pueblo antes que atender reivindicaciones regionalistas. No se desaprovecha la oportunidad de volver a contraponer el patriotismo del proletariado al patriotismo burgués. Madinabeitia, máximo defensor del federalismo plurinacional, dice: «Y no se nos tache de malos patriotas. El amor a España no es incompatible con el que todos debemos profesar a nuestra patria mayor, el mundo, ni a nuestras patrias pequeñas, la región y el Municipio. El mal patriota es el que pospone el amor a España al amor a su región: el catalán que se siente antes catalán que español, por ejemplo» ${ }^{34}$.

Para el PSOE, el cambio de régimen deviene de un movimiento revolucionario general, no particularista ni aislacionista, consecuencia de una nueva conciencia nacional que se ha convertido en republicana, la auténticamente patriótica. Sin embargo, ambas variables (régimen democrático y autonomía regional) parecían inevitablemente ligadas. Así lo reconoció Jiménez de Asúa años más tarde: «la corriente federal estaba mantenida por un corto número de republicanos; pero las concesiones de autonomía eran inevitables» ${ }^{35}$. De ahí su apuesta por el reconocimiento de la realidad histórica regional que puede traducirse en una

32 Ibidem.

33 Ibídem.

34 «Patriotas al cien por cien». El Socialista, 2 de diciembre de 1930. En la misma línea. PRIEGO, Victoria. «Nacionalismo». Democracia, 20 de agosto de 1933.

35 JimÉnez De AsúA, L. El criminalista. Buenos Aires: La ley, 1946, pág. 63. 
estructura federal del Estado, pero sin particularismos desorbitados. Federalismo sí, pero dentro de un proceso constituyente basado en la soberanía nacional. Pero, un Estado también descentralizado, ajeno a las normas e imposiciones del centralismo Restauracionista, que fuera respetuoso con las distintas comunidades sociales existentes en España. Ha sido desde sus orígenes a mediados del siglo XIX el republicanismo, de esta manera, un claro contrapunto de la política monárquica. Frente al carácter censitario, la defensa del sufragio universal, frente al componente católico de la monarquía, el laicismo militante, frente a la centralización, una abierta descentralización, que adoptó expresiones a veces bien distintas en las diferentes familias republicanas y entre los socialistas. En todo caso, esa defensa de la descentralización no constituyó en ningún momento el rechazo del nacionalismo español; por el contrario, siempre los republicanos se manifestaron en favor de España como estado-nación, pero eso sí con una soldadura social, jurídica y territorial dispar de aquella desarrollada por la monarquía isabelina, primero, y por la Alfonsina, más tarde.

Como ha puesto de manifiesto Santos Juliá, ciertamente «no todos en el socialismo esperaban lo mismo de la República ni iban a ella en idéntica disposición política ${ }^{36}$ ». El sector pro-republicano veía en el nuevo régimen una oportunidad de consolidar definitivamente el lugar de la organización obrera en todo el complejo de relaciones laborales y en el Estado. Conforme a su ideología evolutivo-organicista de la marcha al socialismo, pensaban que unas sociedades obreras bien forjadas, sería fundamental para la implantación del socialismo. Sin embargo, el sector de los reformadores iba guiado sencillamente por su liberalismo y su creencia en la democracia como instrumento de transformación social. En cualquier caso, ambos, a la altura de 1931, pensaban que la transformación habría de hacerse dentro de las instituciones de un régimen que, por lo demás, estaban por construir.

La tendencia antifederal va a tener una fuerte presencia en la prensa socialista. En esta línea, un nuevo editorial de El Socialista titulado significativamente «La actual epidemia regionalista ${ }^{37}$, afirma que ésta es reflejo de «la inexistencia de una forma cohesiva hispánica capaz de influir en las grandes corrientes universales». Citando a Menéndez Pidal, que antes había distinguido entre el federalismo como método de organización estatal del regionalismo oligárquico, El Socialista matiza el sentido racional del federalismo orgánico en el sentido de que «autonómicamente, el federalismo sólo posibilita la diferenciación administrativa»,

\footnotetext{
${ }^{36}$ AA.VV. El socialismo en España. Madrid: Editorial Pablo Iglesias, 1986, pág. 233.

37 «La actual epidemia regionalista». El Socialista, 28 de julio de 1931.
} 
reduciéndolo a un plan de descentralización regional y alternando nuevamente con toda libertad los conceptos de autonomía y federalismo. Finalmente, insiste en que la cuestión social, y no la regional, debe ser la preocupación fundamental de los parlamentarios socialistas en las Constituyentes:

«Los Estatutos, la estructuración regionalista, no pueden aportar a España ninguna superación social. [...] El obrerismo y el Socialismo, propugnadores de ideales netamente internacionalistas, ni pueden entretenerse en las entelequias patriarcales y medievales del regionalismo lugareño [...] Por lo tanto, al fundir los moldes de la España nueva, llamaremos a la virtud ideológica estricta de los postulados izquierdistas y sociales para que ellos nos tracen los senderos de nuestro vivir venidero. Federaremos, segregaremos del cuerpo del Estado funciones administrativas para que las regiones con posibilidades autonómicas se desenvuelvan económicamente como quieran. Pero sin tocarle para nada al alma española, sin rupturas ni divorcios» ${ }^{38}$.

Otro socialista que rechaza el federalismo es José M. Francés que escribe: «Costa, en el postulado de su vida, siempre gritó: escuela y despensa. Hoy el que no haya escuelas, ¡no importa! El que muchos hombres tengan hambre ¡no importa! Lo interesante, lo preciso, es ver si creamos unos cuantos Estaditos para que los gobiernen los ineptos, los caciquillos, los que se sienten incapaces de triunfar en una lucha abierta, los que en lugar de ostentar un título de suficiencia exhibirán orgullosamente la partida de nacimiento. Eso es lo importante» ${ }^{39}$. Es importante esta afirmación de Francés porque vuelve a poner de manifiesto que el rechazo viene por motivos ideológicos, la federación de Estados traerá de nuevo lo que los socialistas están tratando de evitar: el caciquismo, los malos gobiernos, etc. No hay un motivo político sobre el rechazo sino que éste viene dado por la ideología.

En la misma línea se expresa Aníbal Sánchez en «Regionalismo y autonomía ${ }^{40}$, cuando destaca el peligro de recuperación del feudalismo por parte de las nuevas élites locales con la excusa de la autonomía, así como la desigualdad de derechos entre españoles que los socialistas, de acuerdo con la resolución congresual, deben combatir:

«Nunca se podrá demostrar que a una región pueda ser otorgado un derecho que no puede serlo a su vez a las demás, si no quiere incurrir en la

\footnotetext{
${ }^{38}$ Editorial de El Socialista, 15 de septiembre de 1931.

${ }^{39}$ FrAnCÉs, J.M. «En torno al federalismo». .El Socialista, 16 de julio de 1931.

${ }^{40}$ SÁnCHEZ, A. «Regionalismo y autonomía». El Socialista, 31 de julio de 1931.
} 
grave injusticia de reconocer privilegios a unos ciudadanos sólo por el hecho de haber nacido en punto distinto dentro de la nación española. Eso es completamente absurdo; y si asi se reconoce, necesariamente se ha de reconocer también que existiendo una misma ley que determine iguales derechos para todos los ciudadanos, los Estatutos regionales no son otra cosa que una distinción perturbadora para barrenar la igualdad social a que todos aspiramos» ${ }^{41}$.

De nuevo la confusión, para este socialista, el federalismo, lejos de representar una posición de autonomía y descentralización igualitaria del poder, es el semillero de la desigualdad y los privilegios entre territorios, pero, sobre todo, entre personas.

La vertiente federal insiste en la diversidad de los pueblos que conforman España así como en su mejor articulación política: «No cabe negar hoy que el régimen federal es el sistema que mejor cuadra a España». La preferencia por este sistema viene expresada por ser el más adecuado para encauzar las diferencias de idioma, cultura y lengua. «El punto diferencia de cada región, en los aspectos de cultura e idioma, y aún es posible la consideración étnica, bien marcado por cierto, serán respetados $\gg{ }^{42}$.

«Abogamos por la desaparición de la pequeña provincia, tal como lo son las muestras, porque su existencia, que no la abona ningún fundamento real, haría costosísimo y difícil el régimen de federación, por lo menos si había de atenderse al modelo implantado en otras partas con Gobiernos autónomos, Parlamentos autónomos, poder judicial y administración autónomos. [...] Una España estructurada a esa base nos parece lo más acertado y lo más indicativo. Seguramente eso mismo o semejante, será lo que nazca de las constituyentes. Otra forma federal, comprendiendo solamente a tres o cuatro Estados-región, tales como Cataluña, Vascongadas y Galicia y las demás en la misma estructura de ahora que eso se habla en algunos sectores, no la juzgamos conveniente. Parecería algo inconcluso y arbitrario. Y desde luego injusto. Saltaría inmediatamente lo de las preferencias y lo de los tratos desiguales. Terminaríamos con al problema catalán o gallego, y empezaríamos con el astur o el aragonés» ${ }^{43}$.

Preocupación de los socialistas era también el idioma oficial a adoptar por parte del Estado: «No creemos que origine dudas, el idioma español. El cultivo del

\footnotetext{
${ }^{41}$ Ibídem.

42 Ibídem.

${ }^{43}$ Ibídem.
} 
idioma vernáculo de cada región y su enseñanza en las escuelas, no nos parece mal del todo, siempre que el de la nación sea el único oficial en toda España. Y esto por una razón muy sencilla: por su mayor extensión, por su mayor dominio en todas partes» ${ }^{44}$.

En Renovación, se hace una distinción clave entre federalismo y autonomismo o descentralización. Utilizando el argumento de la exacerbación del morbo individualista, de este modo el federalismo sería, en esencia, «una doctrina de complexión anarquista. No anarquismo de petroleros, ni de renegados con el actual desarrollo de la sociedad, sino anarquismo en cuento tiene de exacerbación del morbo individualista, en nuestros días totalmente inadmisible» ${ }^{45}$. Los socialistas no debían por lo tanto estar conformes con el federalismo en cuanto que enemigos de toda separación, de toda frontera, «no iban a crear en el propio territorio, las mismas bases que luego abominan». Porque destruir lo construido para dejar al hombre en plena libertad, en un estado de independencia salvaje resultaba absurdo. «Lo constituido es algo que puede transformarse, demolerse cuando se cuente ya con el nuevo sistema que habrá de sustituir al viejo. Destruir porque sí, sin causa ni justificación, para rehacer un nuevo Estado en el que forzosamente el hombre volvería a incurrir en los mismos defectos y se conduciría a la misma situación que lamentamos, sólo puede ser obra de inteligencias tan exaltadas que se alejan a sí mismas de la realidad $\gg^{46}$. No se trataba de que una provincia establezca su propia libertad sino que esa libertad sea repartida desde el poder central. Lo otro es considerado como una labor individual que alimenta el espíritu disgregador. Por esa razón, el federalismo que propugnan los socialistas en Renovación «va de arriba abajo» ${ }^{47}$. «Es la descentralización. Cede algunas atribuciones del poder central a los poderes provinciales, crear, antes que provincias, comarcas regionales, agrupadas no por pueblos, sino por terrenos, psicología y temperamento. Sin bien, por ejemplo, en Cataluña se distingue bien Barcelona de Lérida, Barcelona y Gerona podrían constituir una misma comarca disgregando algunos de sus pueblos. Acostumbrémonos a no crear organizaciones científicas -la provincia, una de ellascon necesidades contrapuestas en muchos de sus pueblos. Creemos poderes directivos -gobernadores, prefectos-, según las necesidades, según la situación de

\footnotetext{
${ }^{44}$ Ibídem.

${ }^{45}$ Editorial de Renovación, 31 de julio de 1931.

${ }^{46}$ Ibídem.

${ }^{47}$ Ibídem.
} 
un núcleo de pueblos determinado» ${ }^{48}$. La única condición es que «siempre exista en España la actuación de un poder central, supremo director» ${ }^{49}$.

Teniendo en cuenta lo anterior, exponen como modelo la situación de las Diputaciones vascas. "Que tienen un presupuesto fuerte, una ayuda del Estado, pero una independencia casi absoluta y cuidan de sus carreteras y tienen en el campo centenares de escuelitas, verdaderos modelos de limpieza, de higiene y de educación para los pequeñuelos en los caseríos. Dejémosle independencia en su actuación $»^{50}$. Esa independencia conlleva autonomía fiscal: «que cada región recaude para sí en sus presupuestos locales». Pero eso «no significa abolir el Ministerio de Hacienda». Para ello habría que hacer de él no una serie de oficinas encadenadas en trámites burocráticos, «sino un poder central dispuesto a prestar apoyo a las provincias y a las regiones que lo necesiten, decidido a apoyar las obras peculiares y propias del Estado, en condiciones de subvenir a los gastos generales y de fiscalizar los ingresos». De este modo, como exponía el editorial de Renovación, podría garantizarse medios económicos para rehacerse ante una tragedia, o por una crisis de trabajo. «Se recurriría al apoyo de las demás compañeras, que, obligadas ahora a buscarse dentro de sí mismas los recursos, no podrían, por muy grande que fuera su voluntad, atenderlas ${ }^{51}$. Por tanto es el poder central el que deberían de intervenir.

En el mismo periódico, la posición federal será sostenida a través de una reflexión sobre la significación de la unión de España a lo largo de los siglos. En primer término, se reflexiona sobre el país. Se trataba de una nación que ha deshecho la derecha. Pero España no siempre fue así. «España ha sido una gran nación. Una nación magnífica. Nuestro país ha producido hombres excelsos. España ha poseído una organización insuperable, perfecta, en relación con otros países de la época. España fue antes del siglo XV insuperable en todo» ${ }^{52}$. De manera que, para los socialistas, España fue grande y dichosa mientras se desenvolvió libremente y sobre todo mientras se gobernó por sistemas de autonomías concejiles y de matizaciones regionales, «dentro de un régimen libre de Cortes y no de reyes tiranos entregada a su propia sazón, energía, instinto y

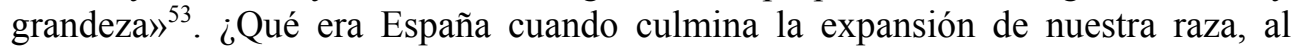

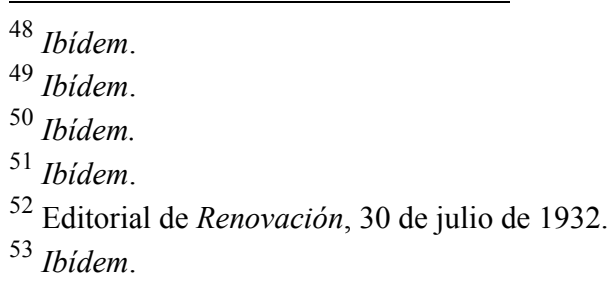


casarse Isabel de Castilla y Fernando de Aragón? ¿Qué es bastante antes? - se cuestionan los socialistas. La respuesta es clara: «una península occidental, en la que íberos con mezcla de indios, cultivados y florecientes, de romanos, de griegos han formado una estirpe inteligente y activa tan llena de matices y complejidades, que puede competir en cualquier rasgo especial con todas las razas ${ }^{54}$. Además, España con la Reconquista, había sufrido en varias nacionalidades perfectamente definidas y evidentes. "Aragón, Castilla, Cataluña, Navarra, Portugal $»^{55}$. Esas nacionalidades - fundidas en un espíritu heroico y liberal - desde entonces hasta ahora tienen para dar cumplida y documentada respuesta. La unión nacional se verificó a través de la fuerza íbera, basada «en la libertad municipal, la libertad regional, órbitas más amplias de la libertad individual, de la libertad humana, regímenes de fuerzas libres que se organizan para dar un fruto colectivo para formar un pueblo robusto, grandiosos, sin precedentes en los anales de la civilización de los pueblos». «Son el modelo político del mundo». «Nacidas al calor de grandes luchas, su alma es clara, varonil y libre ${ }^{56}$. El Íbero, para los socialistas, sea portugués o catalán, ansía siempre la libertad, porque supo ganarla en la lucha. Posteriormente, el liberalismo, que consternaba a Europa, «era prácticamente desconocido en nuestro país». Los reyes no son otra cosa que lo que habían sido siempre: caudillos militares. «Leed, las leyes de Partidas, y leeréis en ellas el agua sana y pura del liberalismo español, la esencia política maravillosa que después copió Inglaterra y que no ha encontrado luego rival en el pensamiento humano ${ }^{57}$. En esa España, los hombres eran libres y las cosas esclavas.

«No como ocurre en la actualidad. ;Pero pronto reformará ese atavismo también la República! Ellos eligen su Consejo y ellos administran su Consejo ¿Quién lo administrará mejor? ¿Quién cuida mejor el comercio y la industria sino los poseedores del comercio y de la industria? A esa autonomía municipal - malintencionados debeladores de la patriotería andante de este siglo $X X-$, a esta autonomía regional, a esta intachable democracia jamás vuelta a ver en ningún otro pueblo de la tierra, a esta tierra corresponde el progreso asombroso de las artes y de las ciencias. Castilla da legisladores y poetas. Cataluña es el emporio incombustible. Toda la península es fuerte» ${ }^{58}$.

\footnotetext{
54 Ibidem.

55 Ibídem.

${ }^{56}$ Ibídem.

${ }^{57}$ Ibídem.

${ }^{58}$ Ibídem.
} 
La unidad nacional se fundó para que al formarse con toda España un gran Estado no se deformara a España, y por lo tanto, no se asesinara a España. Para los socialistas debió hacerse por federación y no por hegemonía, pues de este modo se hubieran conservado la plena libertad del Concejo y de las Cortes. Así lo expone el editorial de Renovación.

«Para esa unidad «hizo falta entonces una alianza, pero no una tiranía. Una gerencia responsable, gerencia condicionada, desde luego, a ser depuesta en el instante de no cumplir con lo pactado. Así se efectuó la unión nacional. $Y$ ahi está firme, destacado y soberano el emblema regional y federal. Tanto monta, monta tanto, Cataluña como Navarra. Nadie ha absorbido a nadie. España es la misma rica, trabajadora, próspera, culta, fuerte, libre» ${ }^{59}$.

Se recurría de nuevo a un argumento de orden histórico, para defender la posición autonomista. Había sido positivo para el progreso de la nación esa organización administrativa que propugnaba un país en que, el éxito histórico de la autonomía de los municipios, convertía ahora en demanda actual construir un Estado federal.

Una posición que no será tan entusiasta en todos los socialistas. Largo Caballero por ejemplo, en las Cortes, durante el debate constituyente, rechaza otorgar competencias en materia social a las regiones. Los argumentos utilizados por Largo no dejan lugar a dudas: «Si España tiene el deber de ratificar los Convenios; si España o el Estado español es el responsable ante la Internacional, del cumplimiento de la legislación y si no la cumple se pueden imponer sanciones ¿es posible que el cumplimiento de las leyes sociales sean las regiones las que tengan jurisdicción para poder llevarlas a cabo? $\rangle^{60}$. Pero además Largo encuentra argumentos de oposición en el mismo establecimiento de los Estatutos, rechazando así una organización autonomista. «Si mañana se aprueban varios Estatutos y en la lucha con el capitalismo, en una de las regiones hay negligencia en el cumplimiento de la legislación social, hasta el punto de que obligue a otras regiones a seguir ese camino y España tiene que responder ante la Oficina Internacional del Trabajo, ¿será justo que porque unas regiones no cumpliesen España incurriera en responsabilidad y pudiera imponérsenos sanciones por incumplimiento de la legislación social? A mi juicio no» ${ }^{61}$. Largo pone el ejemplo de Cataluña:

\footnotetext{
${ }^{59}$ Ibidem.

${ }^{60}$ Diario de Sesiones del Congreso. $\mathrm{n}^{\mathrm{o}} 45.25$ de septiembre de 1931.

${ }^{61}$ Diario de Sesiones del Congreso ${ }^{\circ} 45.25$ de septiembre de 1931.
} 
«esta enmienda yo no la defiendo por espíritu de partido, esta enmienda la defiendo porque hace tiempo han acudido a mi representaciones patronales de Cataluña a pedirme que sea el Estado Español el que vele por el cumplimiento de la legislación social; los otros no han acudido, porque si dejamos en libertad a cada región para aplicarla, es seguro que, con el tiempo, no se cumpliría en ninguna, pues digase lo que se quiera, la competencia industrial de cada región, haría que, la jornada de trabajo excediera las ocho horas, que la protección de la mujer y del niño se burlase para competir con otras regiones y poder concurrir en el mercado nacional o internacional con mayor ventaja para la lucha económica, y el único que puede velar con verdadera imparcialidad por el cumplimiento de esa legislación en todas las regiones, puesto que no tiene interés ni preferencia por ninguna de ellas es el Estado Español. [...] Es más: yo creo que si los señores representantes de Cataluña examinasen esto despacio, con algún detenimiento, verían en seguida que a quien más conviene que la legislación se haga cumplir por el Estado español es a Cataluña, porque ¿quién asegura a Cataluña que mañana otra región, al tener un Estatuto, hará lo mismo y no tendrá negligencias ni descuidos en el cumplimiento de esa legislación para hacer la competencia a Cataluña? ${ }^{62}$.

Eran los intereses trabajadores los que primaban. Una posición indiscutiblemente coherente en el líder socialista - más allá de los procedimientos - que en realidad mostraban desconfianza a una centrifugación del poder por lo que de perjuicio a los trabajadores pudiera suponer. La autonomía para Largo era contraria a la España que propugnaban los socialistas y que descansaba en el pueblo. Pone de manifiesto la celebración de mítines separatistas o autonomistas en Cataluña, Vasconia o Galicia. Estaban en su derecho según Largo. Lo censurable para el líder obrero, era el tono de ciertas peroratas de gallegos y vascongados que todavía motejan de opresor al poder Central y tachaban de tiránico al Estado unitario. «Tales declamaciones fueron regadas con el alcohol separatista y aderezadas con muertas a España». Ni había para Largo tal centralismo y unitarismo ni existía tamaña tiranía. Esos desplantes no eran otra cosa que resabios del antiguo régimen unitario y expansiones de cavernícolas o trogloditas amantes de los jesuitas y enemigos del pueblo y la República» ${ }^{63}$.

De todo lo que hemos expuesto hasta ahora, podemos llegar a algunas conclusiones. Sin embargo, la palabra confederación toma mucha más relevancia cuando se trata de alguna alianza permanente de Estados o alguna asociación o mancomunidad de Estados. Como han señalado José Luis de la Granja, Justo

\footnotetext{
${ }^{62}$ Ibídem.
}

${ }^{63}$ Ibídem 
Beramendi y Pere Anguera, en realidad, pronto se puso de manifiesto algo de lo que ya había indicios anteriores: el ascenso de los nacionalismos sub-estatales durante la crisis de la Restauración que ahora afloraban con fuerza, había contribuido a modificar las actitudes de los partidos políticos de ámbito español respecto de este asunto y, en especial, las de las dos que más importaban ahora pues eran los que forjaban el sistema: republicanos y socialistas ${ }^{64}$.

Como acabamos de ver, el federalismo nunca fue mayoritario ni mucho menos en el discurso del PSOE y a esto no fue ajeno el hecho de una idea fuerte de Estado-nación por influencia del organicismo y el regeneracionismo (como hemos analizado ya), así como la peligrosa perspectiva para los socialistas y la clase obrera, del dominio de los nacionalismos allí donde más proletariado había: Cataluña y el País Vasco. Por ejemplo, para el segundo caso, Prieto tenía pánico a que este territorio se convirtiera en un «Gibraltar vaticanista».

\section{Congreso del PSOE 1931}

El Congreso de julio trata de fijar una posición oficial y unitaria del partido ante el hecho territorial de España y su organización. En él se refleja el abandono de cualquier aproximación federalista y su adaptación a una flexibilidad conceptual consistente en aceptar el autonomismo. Pero siempre como una posibilidad a posteriori, dependiendo de la consolidación de las regiones, y rechazando cualquier planteamiento pactista que implicara compartir la soberanía constituyente del pueblo español.

La opción de la Autonomía y no la de la federación de regiones supuestamente independientes, es la única que puede aceptarse en el proceso constituyente, siempre que la cesión de poder político a las regiones sea relativa y dentro de la soberanía nacional representada en el Pueblo. Dirigentes como el propio Cordero, Aníbal Sánchez, Enrique de Francisco, Julián Besteiro y Joaquín Mencos se refieren al tema, ya en artículos, ya en entrevistas, perfilando una doctrina adaptable a la resolución congresual de julio.

Manuel Cordero, comienza diciendo que «yo no quiero ocultar que la forma federal tiene mis mejores simpatías», $y$, tras constatar que «a la unidad nacional se llegó, no por la vía diplomática, facilitando la evolución de la conciencia colectiva hacia la formación del gran Estado hispánico, sino imponiendo por la brutalidad de la fuerza el imperio de la voluntad de los reyes triunfantes» (interpretación

64 De la Granja, J. L.. Anguera, P. Beramendi, J. La España de los nacionalismos y las autonomías. Madrid: Síntesis, 2001, pág. 114. 
sostenida también por Azaña), se pregunta si federalizar implica volver a «desvincular las regiones de la vida orgánica del Estado», a lo que responde categóricamente: «No. En las regiones serán sustituidas las Diputaciones provinciales [...] por organismos regionales con funciones y facultades bien determinadas, con cierta autonomía para resolver aquellos problemas peculiares de la región, pero sometidos siempre a las conveniencias generales del país». Para acabar sentenciando que «la independencia de las regiones no la defiende ya ningún hombre cuerdo y sensato; la autonomía, regulada orgánicamente, en la estructuración del Estado, sí» ${ }^{65}$. Encontramos una cierta confusión terminológica del concepto federar, en la medida en que se entiende como una manera libre de vincularse con España y, en este aspecto, se cree negativa para el país, puesto que disgrega la voluntad común del país. Cosa distinta era la autonomía que servía como reconocimiento de la región, pero siempre tutelada por el Estado.

Joaquín Mencos lo describe claramente: «El pacto es la única forma de constituir naciones de una forma jurídica, es decir, sin apelar a la violencia, pero no es preciso para organizar naciones ya constituidas [...] España existe ya hace muchos siglos, y el patriotismo nos debe impedir que pueda segregarse de ella nada». La posición de Mencos es la de la existencia de un Estado-nación consolidado que es España con la particularidad que pueda ser organizada administrativamente de un modo distinto al de la Restauración, así, esa organización puede comprender el federalismo que para Mencos, «exige, pues, tan sólo el reconocimiento de la más plena autonomía municipal y regional» ${ }^{66}$.

Julián Besteiro distingue en una entrevista la manifestación de la voluntad autonomista catalana, expresada claramente en el Pacto de San Sebastián y que puede abrirse, eventualmente, «a las demás regiones $\mathrm{o}$, si se quiere, nacionalidades», del proceso de estructuración general de tipo federal: «Pero si se intentase someter a toda España a un esquema de República federal, se cometería a mi juicio un grave error que es preciso evitar ${ }^{67}$. Besteiro no entra en las causas del rechazo del federalismo, pero hay que pensar que, en fondo parte la concepción disgregadora del federalismo.

Aníbal Sánchez afirma: «si el federalismo es unir o atar con lazos más o menos fuertes las relaciones entre los pueblos, es de toda evidencia que sólo puede unirse

${ }^{65}$ Cordero, M. «¿Cómo ha de ser la República?». El Socialista, 23 de mayo de 1931

66 Mencos, J. «La región o el municipio bajo un régimen descentralizado o federal». El Socialista, 24 de junio de 1931.

${ }^{67}$ Importantes declaraciones de Besteiro. «La gran misión del Socialismo en la República». El Socialista, 4 de junio de 1931. 
lo que está desunido», sostiene que es inaplicable a un Estado ya constituido como España. Su concepción es que el federalismo es una opción política para Estados que tienen que articularse política y administrativamente, cosa que ya sucedía en España. Admite que los federalistas ponen en cuestión esta unidad al considerar que no ha sido voluntaria, sino forzada (de nuevo la confusión con la confederación), pero incluso esta interpretación histórica, asumida por otros dirigentes socialistas (Bestiero o Araquistáin, por ejemplo), es matizada por Sánchez: «la unidad impuesta contra la voluntad de los pueblos, que en algunas regiones se ha convertido en un vidrioso y exaltado sentimentalismo, a nuestro juicio no responde tampoco a la verdad, por lo menos a toda la verdad, porque si no se contó con la voluntad de los pueblos para hacer la unión, tampoco se hizo contra su voluntad. Desgraciadamente, entonces no era el pueblo, sino sus señores, quienes hacían y deshacían». Sánchez insiste en que la única constitución razonable es la basada en «todo el país español, tal y como políticamente ha sido objeto de constitución hasta ahora; es decir, una sola nación, quedando, por tanto, excluida toda idea federalista ${ }^{68}$.

En este caso, habría que entender el contexto, esto es, el proceso constituyente, en el que se debate qué hacer con el mandato popular. Los socialistas, como hemos visto, no tienen una gran formación teórica puesto que no son capaces de definir políticamente el significado del federalismo, y tampoco, proponer una alternativa clara, ya que, la autonomía, tampoco es analizada, ni se establece un significado político de la misma. Hay que partir por tanto de este hecho, para explicar y entender las declaraciones de los líderes en el Congreso y en la prensa socialista. Por ejemplo, en sendos artículos posteriores ${ }^{69}$, Sánchez defiende abiertamente la fórmula unitaria, la cual no puede ser unilateralmente «modificada por el deseo ni la conveniencia de ningún sector, sino porque así lo deseara la mayoría de toda la nación ${ }^{70}$. Con ello advierte contra los planteamientos unilateralistas de los nacionalismos que pretenden el derecho de autodeterminación o un Estatuto constitucional no negociado por las Cortes Constituyentes. «La forma unitaria, por sí sola, no puede satisfacernos; pero la consideramos más apta para responder a los fines que anteriormente señalamos», esto es, para la acción política igualmente unitaria del socialismo español con el fin de «traer a los hombres mayor bienestar y más justicia social» ${ }^{71}$. De nuevo la carencia de una reflexión profunda en términos

${ }^{68}$ SÁnCHEZ, A. «Unitarismo y federalismo». El Socialista, 28 de junio de 1931.

69 Sendos artículos en El Socialista, «Unitarismo y federalismo II» 1 de julio de 1931. «Regionalismo y autonomía» 31 de julio de1931.

${ }^{70}$ SÁnCHEZ, A. «Unitarismo y federalismo II». El Socialista. 1 de julio de 1931.

${ }^{71}$ Ibídem. 
políticos del significado de la articulación político-administrativa de España, estando ésta en función de los intereses y la unidad de la clase obrera. Sánchez define el programa socialista como la continuación de la acción parcialmente nacionalizadora del Estado liberal, centrándose en la construcción de obras públicas, comunicaciones y códigos comunes, que no deben ser troceados por un ímpetu federal: «un esfuerzo común con leyes iguales para todos ha creado la nación española y en comunidad debe continuarse para engrandecerla» ${ }^{72}$. No hay muchas diferencias con la idea de hacer nación expresada por Indalecio Prieto al frente del Ministerio de Fomento. España como país y España como comunidad política tiene que ser política y administrativamente acorde a los intereses de la clase obrera.

Finalmente, hay que poner de manifiesto que los socialistas rechazan notoriamente que la transformación del Estado tenga que venir necesariamente por un proceso federal que vaya más lejos de la descentralización regional de servicios: «en el régimen unitario no hay nada que impida el perfeccionamiento de la administración del Estado, descentralizando servicios y funciones para evitar tramitaciones lentas [...], pero eso no tiene nada que ver con estatutos, ni con personalidad de las regiones, ni con federalismo alguno» ${ }^{73}$. Esta declaración deja de nuevo patente la ausencia de una idea sobre el significado político de la descentralización y, además, muestra un cierto desdén hacia todo lo que conlleva. Ciertamente, ya en los años 30, e incluso desde los partidos del turno durante la Restauración, se había asumido que el reconocimiento de una región era políticamente sinónimo de descentralizar, cosa que no podría hacerse bajo un Estado unitario. Por ello, sorprenden este tipo de afirmaciones que no manifiestan un conocimiento político de la materia, sino más o menos un rechazo vago y primario.

En medio de este confusionismo sobre el término federal, la doctrina que se va desgranando en el PSOE ante el Congreso Extraordinario y el debate constituyente se caracteriza por estos tres aspectos fundamentales:

En primer lugar, la unidad nacional de España como marco político, lo que ya se hiciera en el momento de la constitución del Partido Socialista en 1879. Mal que bien, y a través del proceso histórico, España es un Estado nacional que debe perfeccionarse (ya hemos analizado en qué consistía hasta el momento ese perfeccionamiento). Esta posición está presente desde los orígenes del Partido

\footnotetext{
${ }^{72}$ Ibidem.

${ }^{73}$ Ibídem.
} 
Socialista, pero empieza a tener presencia en los discursos y en la prensa cuando los socialistas adoptan un cierto discurso de país con motivo del rechazo de la Guerra de Cuba y Marruecos y durante los últimos años de la dictadura de Primo de Rivera, esto es, en las postrimerías de la República, cuando se hace presente la obra transformadora que tiene pendiente hacer una nueva España. En segundo lugar, no se puede federar en el sentido de unir lo que ya está unido. Para hacerlo habría que disgregarlo previamente. Luego el federalismo construido a través de pactos entre territorios independientes -que es lo que se intuye en los líderes socialistas a tenor de lo que hemos visto antes- no es aplicable al caso español. En tercer lugar, Cataluña requiere una solución autonómica sin llegar al pacto federal. Es solo un caso particular. España no está en condiciones de ir más allá, de generalizar la autonomía ni la descentralización general que propone Ortega en la Redención de las provincias. Ha de ser un proceso abierto y gradual en función del desarrollo socioeconómico y político de las regiones. Se seguirá, pues, la doctrina de Azaña: la autonomía como consecuencia y no como causa de desarrollo regional.

El PSOE celebra su Congreso Extraordinario días antes de la constitución de las Cortes (14 de julio), para definir su actuación ante la discusión constitucional. El debate sobre la cuestión regional que es mínimo, tiene lugar en la sesión del 13 de julio, y en él se acepta el autonomismo per se, y se rechaza el federalismo. Concretamente, la resolución octava indica:

El Partido Socialista, por su carácter internacional y orgánico, apoyará toda reivindicación autonomista encaminada a lograr el reconocimiento de la personalidad regional; mas, a fin de no favorecer movimientos equívocos, debe pedir garantías de la vitalidad de los mismos, y a este objeto exigir la previa consulta al pueblo antes de asentir al Estatuto autonómico de una personalidad regional $l^{74}$.

En la resolución hay que analizar dos cuestiones: En primer lugar, la aceptación de la autonomía regional. En segundo lugar, se insiste en la viabilidad de las autonomías regionales y la celebración de un referéndum previo.

\section{EL PSOE EN EL DEBATE CONSTITUYENTE:}

Desde julio hasta diciembre, las Cortes discutieron el proyecto de Constitución hasta que finalmente se aprobó en la última de esas fechas. Este proyecto fue dirigido y redactado por el prestigioso letrado Luis Jiménez de Asúa.

\footnotetext{
${ }^{74}$ Actas Congreso Extraordinario de 1931 del PSOE. Madrid: Gráfica Socialista, 1932.
} 
Particularmente virulentos resultaron los debates en los que se trató la cuestión religiosa. Finalmente se impuso la postura mayoritaria en la cámara y se proclamó la libertad religiosa y el carácter laico del gobierno, desvinculándose totalmente de la Iglesia. Tal punto alcanzó el enconamiento, que en un momento determinado llegó incluso a dimitir el propio presidente republicano en un intento de evitar el anti catolicismo que se proponía incluir en la misma.

En cualquier caso, la Constitución aprobó la prohibición de que las órdenes religiosas pudieran ejercer el comercio, la industria y la enseñanza, lo que resultó a la larga un grave perjuicio desde el punto de vista educativo, ya que la Iglesia que casi monopolizaba el mundo de la educación, no podía ser sustituida tan rápidamente por la enseñanza pública, a pesar del enorme esfuerzo que se hizo desde el gobierno durante los dos años siguientes.

También se prohibió el mantenimiento económico de la Iglesia con fondos públicos, que detraía una parte relativamente importante del presupuesto total del Estado hasta entonces. Todos esos planteamientos de Azaña y de los republicanos de izquierda fueron votados con entusiasmo por el PSOE.

Fernando de los Ríos es el ponente en las cortes constituyentes de la II República, y, así, realiza un discurso de carácter global sobre la Constitución republicana. En primer lugar, reflexiona sobre la naturaleza del poder concibiéndolo como «un poder querido, deseado, hijo legítimo de la voluntad de la comunidad española; es una creación de la voluntad jurídica de la comunidad democrática española». De los Ríos quiere destacar el impulso de los españoles demócratas -es decir, de los republicanos- en un proceso único y falto, pues, del carácter territorial propio de otro federal y pactista.

Para el PSOE, el proceso constituyente republicano es un proceso nacional, no federal: De los Ríos con este discurso no hace sino trasladar a las Cortes la tesis formulada dos meses antes en el Congreso de su partido. Como ha explicado Gillespie, los socialistas defendían que la transformación nacional pasaba por «defender la ascensión de las clases medias mediante la democratización del Estado español, una reducción del poder de la Iglesia y un aumento de las oportunidades de educación ${ }^{75}$. Y todo a través de la República. No había otro régimen capaz de subvertir la situación de la patria.

De acuerdo con estos planteamientos, De los Ríos reclama dos cosas necesarias para la mayoría democrática: poder político y una economía planificada, capaz de

${ }^{75}$ Gillespie, R. Historia del Partido Socialista Obrero español... pág. 57 
transformar - conforme a lo que venía defendiendo el PSOE desde la Restauraciónla fisonomía del país, propiciando su transformación y conteniendo un cambio en la estructura de clases. Así como una política exterior internacionalista «porque responde a nuestro sentido de patria», que implica «un sentido ecuménico de la política $»^{76}$.

Ecuménico, no nacionalista. Y frente al federalismo general que proponían incluso los primeros socialistas frente a los nacionalismos periféricos, De los Ríos defiende el gradualismo compartido con las izquierdas republicanas: «no era posible, a mi juicio, recoger la tradición formalista y unitaria del siglo XIX y darle una vestidura federal a todas las regiones. (...) No; es en función de una necesidad social y para vestir jurídicamente esa necesidad como surge el principio de la autonomía de las regiones con personalidad histórica» ${ }^{77}$. En este punto, De los Ríos introduce otro elemento particular de la discusión, cual es el de la generalización de la autonomía. Sobre la misma, los planteamientos de los federalistas coincidirán más con los de Ortega que con los de la mayoría republicano-socialista, que entiende la Autonomía como un régimen especial para algunas regiones y no generalizable. En el subconsciente de muchos socialistas pervivía la idea de que el federalismo suponía la generalidad del autogobierno, mientras que la autonomía significaba excepcionalidad (el de Cataluña, obviamente y, como mucho, el de el País Vasco).

En opinión de De los Ríos, el reconocimiento coherente de la variedad interna de España obliga a no considerar regímenes generalistas e igualitarios de base porque la base no es la misma. De hecho, el proceso deberá ser gradual y deberá partir de la comprensión del centro castellano a la variedad intrínseca de España para lo que no es conveniente un sistema estrictamente racionalista de federalización o comarcalización artificial. La Castilla que «tal vez por necesidad (sin duda, no tal vez) organiza el Estado en forma centralista» ${ }^{78}$, en este momento histórico su genio político la lleva a admitir «un nuevo ideal de Estado» ${ }^{79}$ respetuoso y reconocedor de dicha variedad. De los Ríos asigna, pues, a la Castilla que, entre otras gestas más discutibles, civilizó a América, la misión de transformar el Estado con los demás pueblos que lo forman, pero asignándole el papel de impulsora y guía.

${ }^{76}$ Diario de sesiones del Congreso, $\mathrm{n}^{\circ} .32,3$ de septiembre de 1931, págs. 749-753.

${ }^{77}$ Ibidem.

${ }^{78}$ Diario de sesiones del Congreso, $\mathrm{n}^{\circ}$. 32, 3 de septiembre de 1931, págs. 749-753.

${ }^{79}$ Ibidem. 
Y por imperfecta que fuera esa construcción nacional desde el centro, De los Ríos se preguntaba: «ipor qué la periferia o alguno de sus pueblos no atrajo sobre sí la obra grandiosa de reconstruir sobre bases distintas al Estado español? $\rangle^{80}$. Esa imperfecta unidad central, pretendidamente homogénea, ha provocado que sean las regiones «órganos flácidos, carentes de vitalidad», por lo que siete años después sigue desaconsejando la generalización del autogobierno.

De los Ríos es categórico sobre la doble debilidad: «si Castilla quiso demasiado, el resto de España ha querido, hasta hoy, políticamente, con poquedad excesiva». La solución será, en su opinión, "conciliar en la unidad de un querer la rica variedad de los quereres, hoy débiles, de sus pueblos mediterráneos y norteños» ${ }^{81}$. La «unidad en la variedad» pimargalliana, pero sin poner en cuestión la unidad de la soberanía nacional.

Trasladándolo al campo socioeconómico -máxima preocupación del PSOE entonces-, rechaza la interpretación inspirada en el organicismo de Saint-Simon y Proudhon y más tarde de Bakunin, que tan vehementemente rechazó Marx por la que las asociaciones obreras tienen una soberanía concurrente con las del Estado en orden a organizar la voluntad del proletariado: «Para nosotros, el Sindicato es el órgano de gestión; por encima de él está el juicio de carácter político, al cual tiene que estar subordinado» ${ }^{82}$.

Era un aviso para «las fuerzas catalanas», que permiten el sindicalismo anarquista como si fuera un Estado dentro del Estado, en el que no cabe inmiscuirse sin su autorización ni que sea (así lo acusan los socialistas) para el cumplimiento de la legislación republicana. Un Estado económico fuerte requiere, en la mentalidad de los socialistas, importantes competencias en materia financiera, fiscal y social.

Se trataba por tanto de dar carácter y notoriedad en la plasmación de la personalidad de la región a otras regiones que hasta ese momento no habían tenido voz activa en la construcción de la nación. Aunque los socialistas como hemos visto ponen una serie de límites a su política autonomista. En concreto, la derivación de la Autonomía del marco constitucional español (como veremos después, los socialistas van a salir al paso de las maniobras de Maciá). Pero también rechazan la autonomía como expresión de la voluntad de las regiones, o lo que era lo mismo, el rechazo a una generalización de autonomías regionales (el

\footnotetext{
${ }^{80}$ Ibídem.

${ }^{81}$ Ibídem.

${ }^{82}$ Ibídem.
} 
caso de Cataluña, el País Vasco o Galicia) no podía extenderse allá donde no hubiera una conciencia regional con raíz histórica. Además, la estructuración de la autonomía regional sobre principios democráticos y republicanos, lo que apuntaba a impedir un temor que era patente en los socialistas, esto es, que determinadas regiones autónomas pudieran constituirse en bastiones de la reacción y de la derecha, o del nacionalismo, siempre conflictivo con los intereses socialistas. La tolerancia al autonomismo, plasmada en la Constitución, encontraba, como hemos visto, para los socialistas, un límite muy claro: siempre que la soberanía no fuese compartida, sino permaneciese intacta en el centro del sistema.

Pero sobre todo, había que asegurar la preeminencia del Estado. Se trataba por tanto de un argumento histórico vinculado a un problema no resuelto de reparto de poder. Como bien ha señalado Juan Pablo Fusi, el liderazgo y tal vez, las concepciones más sólidas en la materia estaban en Manuel Azaña ${ }^{83}$. Sin él los socialistas no hubieran propugnado o votado una autonomía para Cataluña. Los socialistas, en esta materia, siguen por tanto las posiciones de Azaña sin tener, como hemos visto anteriormente, posiciones elaboradas y claras sobre el tema. Sin embargo, como también hemos comprobado, los socialistas, en cierto modo, se contagiaron de las concepciones nacionales de Azaña y los partidos federales. El españolismo de Azaña tenía una doble raíz: el regeneracionismo republicano y la obsesión noventayochista por el ser de España (los socialistas barnizan el historicismo con argumentos materialistas). En todo caso, el rasgo común es el sentimiento profundo de preocupación por España, de la vía regeneracionista que representaba la II República en las relaciones entre Cataluña, País Vasco y España. Además, la República era el régimen esencialmente nacional, algo que los socialistas compartían a medias, puesto que, para ellos, España era, sobre todo, el lugar donde encontraba la redención el pueblo, si la República no cumplía con esa condición, los socialistas debían seguir forjando esa identidad en solitario o por otros medios. Liderados por Azaña, finalmente los socialistas manifestaron la necesidad de reestructurar el Estado y de otorgar a los pueblos del mismo que manifestasen conciencia histórica diferenciada la autonomía que demandase realmente la voluntad popular. En cualquier caso, la invocación de Marx y la apelación a la nación, podían implicar para Donald Sassoon un concepto amplísimo de la política y lo político como forjador de realidades nuevas. Podían abarcar: exigencias a corto plazo como la mejora de las condiciones laborales; reformas nacionales como el fomento de obras públicas o los planes de pensiones, esquemas globales como la planificación económica y un nuevo sistema legal, cambios políticos de gran calado como la extensión del sufragio, proyectos utópicos como

${ }^{83}$ FUSI, J.P. La evolución de la identidad nacional. Madrid: Temas de hoy, 2000, pág. 252. 
la abolición del Estado, etc. Todas estas exigencias podían encarnarse en un solo proyecto omnicomprensivo a despecho (o quizá a causas) de su contradictoria naturaleza ${ }^{84}$.

Imponer la nueva España, significaba hacer hegemónica los principios de la cultura política nacional de los socialistas. Ahora, la nueva España sería el resultado natural de la evolución del país. Como acertadamente ha señalado Julio Aróstegui, el advenimiento de la II República era la desembocadura del periodo de la contemporaneidad de la Historia española en el que se había consolidado un tipo de sociedad y un régimen político que representaba bien las realidades, las contradicciones y carencias que había llevado la revolución liberal. El advenimiento de la Segunda República respondía indudablemente a esa trayectoria compleja y sincopada de los cincuenta años anteriores cuanto menos. En consecuencia, la República significó cosas bien distintas según los intereses, las expectativas, las adscripciones sociales, políticas e ideológicas y la pertenencia a comunidades diferenciadas en su historia de los españoles al comenzar la década de los años $30^{85}$.

La República, con su política regionalista, vendría a satisfacer viejas querencias y apetencias españolas. El problema de la estructura del Estado era de vital importancia. Así, por una parte, se huía del modelo de Estado unitario, propio de la Restauración; y se huía del esquema Federal, el cual había sido el modelo que se pretendió llevar a cabo en la I República. Pero, el compromiso de otorgar autonomía a las regiones exigía encontrar una nueva fórmula. De esta manera, apareció el novedoso concepto de Estado Integral, con el cual se pretendió evitar los evidentes problemas que presentaban los dos modelos anteriormente indicados.

La formulación del mismo la realizaron Luis Jiménez de Asúa, que lo defendió en su discurso pronunciado ante las Cortes Constituyentes, el 27 de agosto de 1931; y Fernando de los Ríos, que lo hizo en su discurso pronunciado ante las Cortes Constituyentes, el 3 de septiembre de 1931.

Con la fórmula del Estado Integral apoyada por el PSOE, no se pretendió por lo tanto una reorganización global del Estado español, sino solo satisfacer las aspiraciones federales de los catalanes, sin deshacer, por otra parte, la unidad entre el resto de las regiones españolas, las cuales, en su inmensa mayoría, eran unitarias.

\footnotetext{
${ }^{84}$ SAssoon, D. Cien años de socialismo. Barcelona: Edhasa, 1996, pág. 31.

${ }^{85}$ Aróstegui, J. Por qué el 18 de julio y después. Madrid: Flor del viento, 2006, pág. 207.
} 
Los creadores del concepto Estado Integral pretendieron exclusivamente solucionar el problema catalán, pero no previeron apenas su posible aplicación a otras regiones españolas. Pese a ello, la Constitución permitió que otras regiones pudiesen acogerse al nuevo modelo autonómico, siempre que fuese ratificado y graduado por las Cortes. De esta forma, la idea defendida por José Ortega y Gasset, de establecer la autonomía por igual para todas las regiones españolas, fue la que se adoptó finalmente.

Sin embargo, para comprender el alcance y significado del concepto Estado Integral, debemos de consultar detenidamente la magnífica obra de Luis Jiménez de Asúa titulada Proceso histórico de la Constitución de la República española, publicada, en 1932. En ella, el autor, tras declarar su limitado conocimiento sobre el Derecho Constitucional, recordemos que Jiménez de Asúa era penalista y discípulo de Constancio Bernaldo de Quirós, confiesa que la máxima preocupación de las Cortes Constituyentes fue la referente a la estructuración de España en un régimen unitario o federal. Así, «dividida hoy la opinión entre uno y otro sistema, fácil hubiera sido pronunciarse por cualquiera, ya que en apoyo de ambos se dan razones de gran peso dogmático e histórico. No obstante, la Comisión ha entendido preferible... no teorizar sobre tema tan grave, sino apoyarse en la innegable realidad de hoy y abrir camino a la posible realidad de mañana ${ }^{86}$.

Las provincias, tras un siglo de existencia, habían adquirido personalidad y relieve y casi nadie en España se oponía a esta organización del territorio nacional. Por ello, «hubiera sido pues, arbitrario trazar sobre el papel de una República federal que, por lo visto, no apetece la generalidad del pueblo a quien había de serle impuesta. Mas con igual claridad, en otras regiones españolas han surgido o apuntan anhelos de personalidad autónoma, en términos tan vivos, con razones tan fuertes y con apasionamiento tan considerable, que el cerrar los caminos a su expansión sería, sobre una injusta negación del sentido de libertad, una insigne

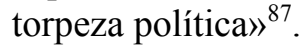

\section{CONCLUSIÓN}

El programa político de los socialistas durante la II República comprendía una transformación de las instituciones y de la estructura de clases. Por este motivo, la cuestión de la organización del Estado es concebida siempre bajo una perspectiva de clase. Son los intereses de la clase trabajadora los que entran en juego a la hora

\footnotetext{
${ }^{86}$ JimÉNEZ DE AsúA, L. Proceso histórico de la Constitución de la República española. Madrid: Ed. Reus, 1932, págs. 5-6.

${ }^{87}$ Ibídem, pág. 6.
} 
de teorizar sobre concepciones tan amplias como el internacionalismo que es entendido, en sentido amplio, como solidaridad entre pueblos a favor del progreso colectivo, la misma organización del estado en donde el debate está entre unitarios y federalistas y donde los criterios territoriales no son los más importantes, puesto que ambas opciones son concebidas más como respuestas a los intereses egoístas de las burguesías nacionalistas periféricas e incluso el nacionalismo de la derecha estatal. Fruto de esos debates es la posición del partido en el debate constitucional, donde el PSOE tiene como objetivo fundamental, la construcción de un Estado fuerte capaz de impulsar la transformación de la clase trabajadora y frenar los impulsos retardatarios del nacionalismo. 